\title{
Exploring the Association Between Sport Participation and Symptoms of Anxiety and Depression in a Sample of Canadian High School Students
}

\author{
Jessica Murphy, Karen A. Patte, Scott T. Leatherdale \\ and Philip Sullivan \\ University of Waterloo \\ Brock University
}

\begin{abstract}
The mental health benefits of physical activity may relate more to the context of the behavior, rather than the behavior of being active itself. The association between varsity sport (VS) participation, depression, and anxiety symptoms was explored using data from 70,449 high school students from the Cannabis use, Obesity, Mental health, Physical activity, Alcohol use, Smoking, and Sedentary behavior study. The model adjusted for potential covariates; interactions by sex and participation in outside of school sport (OSS) were explored. Overall, 70\% and $24 \%$ of respondents met or exceeded cutoff values for depression and anxiety, respectively. Students participating in VS had lower symptoms of anxiety and depression compared with nonparticipants. Results were consistent regardless of OSS participation; associations were strongest among students who participated in both VS and OSS and males. Participation in VS may prove beneficial for the prevention and/or management of depression or anxiety symptoms, particularly among males. An additive beneficial effect of OSS on depression and anxiety scores may exist.
\end{abstract}

Keywords: CESD-R-10, GAD-7, mental health, student-athlete

Mental illnesses are among the leading causes of burden across the lifespan (Vigo, Thornicroft, \& Atun, 2016). Adolescence is a critical period of development, with numerous physiological, social, and lifestyle changes. It is during this transitional life stage that many mental illnesses have their onset, or existing symptoms are exacerbated (Remschmidt, 2013). Based on U.S. epidemiological survey data, the 12-month prevalence of any DSM-IV (Diagnostic and Statistical Manual of Mental

\footnotetext{
Murphy, Patte, and Sullivan are with the Faculty of Applied Health Sciences, Brock University, St. Catharines, Ontario, Canada. Leatherdale is with the School of Public Health and Health Systems, University of Waterloo, Waterloo, Ontario, Canada. Murphy (jm09ah@brocku.ca) is corresponding author.
} 
Disorders - 4th Edition) disorder among U.S. adolescents aged 13-17 years old was $40.3 \%$; anxiety disorders were the most common, followed by behavioral (e.g., attention-deficit/hyperactivity disorder, oppositional-defiant disorder) and mood (e.g., major depressive disorder, bipolar I or II disorder) disorders (Kessler et al., 2012). The prevention and early intervention of mental illness among youth is a public health priority given their short- and long-term negative repercussions. During adolescence, depression can contribute to academic underachievement (Fergusson \& Woodward, 2002), risky behaviors, and self-harm (Auerbach, Tsai, \& Abela, 2010; Auerbach et al., 2014) and, in the long term, lead to premature mortality (Archer, Kuh, Hotopf, Stafford, \& Richards, 2018), subsequent mental illness, and suicidality (Clayborne, Varin, \& Colman, 2019; Fergusson, Boden, \& Horwood, 2007).

Physical activity is often suggested as an economical strategy for the prevention and management of depression and anxiety at the population level (Carek, Laibstain, \& Carek, 2011; Gaudlitz, von Lindenberger, Zschucke, \& Ströhle, 2013; Pelletier, Shanmugasegaram, Patten, \& Demers, 2017). In adolescent populations, physical activity has been shown to have numerous positive effects, including improvements in sleep, self-esteem, and psychological distress (Barth Vedøy, Anderssen, Tjomsland, Skulberg, \& Thurston, 2020; Biddle, Ciaccioni, Thomas, \& Vergeer, 2019; Dale, Vanderloo, Moore, \& Faulkner, 2019; Poitras et al., 2016). Recent reviews support the benefits of physical activity for youth mental health, particularly depressive symptoms and self-concept (Biddle et al., 2019; Dale et al., 2019). However, several prospective studies of nonclinical populations have found weak or null effects for physical activity on depressive symptoms, and the evidence supporting anxiety is limited and inconsistent (Biddle et al., 2019; Dale et al., 2019; Patte, Faulkner, Qian, Duncan, \& Leatherdale, 2020).

Some research indicates that mental health benefits may relate more to the context of physical activity, rather than the behavior of being active itself (Brunet et al., 2014; Doré, O’Loughlin, Beauchamp, Martineau, \& Fournier, 2016; Evans et al., 2017; Lubans et al., 2016). For instance, participation in team-sport and informal group activities was found to be inversely associated with depressive symptoms relative to individual physical activity (Doré, O'Loughlin, Schnitzer, Datta, \& Fournier, 2018). Furthermore, Doré et al. (2018) identified that there was a controlled direct effect of physical activity volume on the association between participation in team sport and positive mental health, suggesting that there is no benefit of increasing the volume of physical activity and that it is the context of team sport that provides the benefits to mental health. The context of team sport is believed to be beneficial to mental health as it offers an opportunity for social interaction, thereby strengthening social networks and perceived feelings of support and integration (Doré et al., 2018; Eime, Harvey, Brown, \& Payne, 2010; Eime, Young, Harvey, Charity, \& Payne, 2013).

The effects of physical activity on mental health have also been explored in the context of sport. Existing research suggests a beneficial effect of sport on anxiety, depression, and general mental health and well-being (Breistøl, Clench-Aas, Van Roy, \& Kjærsti Raanaas, 2017; Doré et al., 2016; McMahon et al., 2017). However, research indicates that this relationship may vary by factors such as sport type and level. For instance, Breistøl et al. (2017) found Norwegian students participating in sport to have fewer mental health symptoms (emotional, conduct, hyperactivity, and peer problems) than those who did not participate in sport. 
This beneficial relationship was present for both competitive and noncompetitive sport but was stronger among youth participating at a competitive level (Breist $\varnothing 1$ et al., 2017). When comparing sport type, regardless of competitive level, Breist $\varnothing 1$ et al. (2017) found that team-sport participation was associated with fewer mental health symptoms as compared with individual sport. A similar conclusion was drawn by McMahon et al. (2017) in a representative sample of European adolescents; those in team sport had the lowest anxiety and depression symptoms and the highest well-being scores. However, a significant difference in anxiety and depression symptoms between team and individual sport participation existed in female athletes only (McMahon et al., 2017). In addition to sex, the relationship between team sport, anxiety, and depression may be influenced by the total volume of moderate to vigorous physical activity (MVPA; Doré et al., 2016, 2020) and age (Doré et al., 2016).

Similar to cross-sectional research, results from longitudinal studies suggest a complex relationship between adolescent sport participation and mental health later in life. Participation in sport as an adolescent was associated with a significant decrease in symptoms of social anxiety and loneliness 1 year later (Brière et al., 2018). A decrease in these symptoms, as well as depressive symptoms, were greater in adolescents who had high baseline values for these variables (Brière et al., 2018). These beneficial effects of sport participation did not differ by sociodemographic characteristics, sport type, or frequency of participation (Brière et al., 2018). Conversely, Jewett et al. (2014) found a positive effect of sport participation on depressive symptoms, perceived stress, and self-rated mental health 3 years later. After controlling for baseline mood disorders, sex, age, extracurricular sport participation, and parental education, participation in high school sport predicted significant improvements in all three mental health measures (Jewett et al., 2014). In the same sample, Sabiston et al. (2016) found that the association between high school sport participation and depressive symptoms may be influenced by sport type. After controlling for age, baseline depression, sex, and parental education, it was found that years of involvement in team sport, but not individual sport, was associated with lower depressive symptoms 3 years later (Sabiston et al., 2016).

The short- and long-term relationship between adolescent sport participation and mental health appears to be influenced by several factors. It remains unclear how age, sex, sport type, competitive level, environment, and intensity of physical activity impact this relationship (Doré et al., 2016). Some of these questions could be answered if common study limitations were addressed. For instance, samples are often restricted to single geographic or sociodemographic areas, preventing generalization of results to a wider population (Brière et al., 2018; Doré et al., 2016; Jewett et al., 2014; Sabiston et al., 2016; Snyder et al., 2010). Furthermore, the data used in previous studies were collected in 2002 (Breistøl et al., 2017), 2006-2008 (Guddal et al., 2019), and 2008/2009 (Jewett et al., 2014; Sabiston et al., 2016); as such, these data may be considered out of date. To better explore the complex relationship between adolescent sport participation and mental health, large population-level research using modern data is needed. As such, the objective of this study is to explore the association between sport participation and symptoms of depression and anxiety in a large cohort of Canadian high school students. This association will be determined after controlling for relevant confounders, including 
sleep, MVPA, screen time, and age. In addition, given the disparities in internalized symptoms (Garnefski \& Kraaij, 2018; Guddal et al., 2019; Kessler et al., 2012) and sport participation (Slater \& Tiggeman, 2011), sex differences in the relationship between sport involvement and mental health will be examined.

\section{Methods}

\section{Design}

Cross-sectional student data were used from Year 7 (2018/2019) of the COMPASS (Cannabis use, Obesity, Mental health, Physical activity, Alcohol use, Smoking, and Sedentary behavior) study (Leatherdale et al., 2014). Year 7 data were used as this year had the largest student-level sample and the most recent complete wave of data available from the COMPASS host study. The COMPASS study is an ongoing (2012-2021) prospective study designed to collect hierarchical longitudinal data from students in Grades 9 through 12 and the secondary schools they attend (Leatherdale et al., 2014). School boards and schools were purposefully selected based on whether they permitted active-information passive-consent parental permission protocols (Leatherdale et al., 2014), which are critical for collecting robust mental health data among youth (Chartier et al., 2008; White, Hill, \& Effendi, 2004). All students attending the participating secondary schools were eligible to participate and could decline at any time. Once annually, COMPASS student questionnaires are completed by wholeschool samples during class time. Further details of COMPASS methods are available online (https://uwaterloo.ca/compass-system/) or in print (Leatherdale et al., 2014). All procedures were approved by the University of Waterloo (ORE 30118) and all appropriate school board ethics committees as required.

In Year 7, data were collected from 74,501 students in 136 secondary schools in Ontario $(n=61)$, Alberta $(n=8)$, Quebec $(n=52)$, and British Columbia $(n=15)$. The participation rate for Year 7 was $84.2 \%$, with missing respondents primarily a result of scheduled study periods or absenteeism on the day of data collection.

\section{Measures}

Depression symptoms. Symptoms of depression were measured using the 10item Center for Epidemiologic Studies Depression scale-Revised (CESD-R-10; Andresen, Malmgren, Carter, \& Patrick, 1994; Radloff, 1977; Zhang et al., 2012). Items assessed characteristics of clinical depression, including negative affect, anhedonia, and somatic symptoms, such as "I felt everything I did was an effort," "I could not get 'going," difficulty concentrating, sleeplessness, and feelings of hopelessness. Students were asked how often they experienced each symptom within the last 7 days, with the response options "none or less than 1 day," "1-2 days," "3-4 days," or "5-7 days." Responses were scored from 0 to 3, respectively, and summed. Higher total scores indicate greater depressive symptoms. The scale has demonstrated validity in adolescent populations (Bradley, Bagnell, \& Brannen, 2010; Haroz, Ybarra, \& Eaton, 2014). Internal consistency in the current study was acceptable $(\alpha=.746)$. A score of 10 or more is indicative of clinically relevant depression symptoms (Radloff, 1977). 
Anxiety symptoms. Symptoms of generalized anxiety were measured using the 7-item Generalized Anxiety Disorder scale (GAD-7; Spitzer, Kroenki, Williams, \& Löwe, 2006). The seven items consisted of symptoms of "feeling nervous, anxious, or on edge," "trouble relaxing," "not being able to stop or control worrying," "feeling so restless that it is unable to sit still," "becoming easily annoyed or irritable," and "feeling afraid as if something awful might happen." Students were asked how often they experienced each symptom in the last 2 weeks, with the response options "not at all," "several days," "over half the days," or "nearly every day." Responses were scored from 0 to 3, respectively, and summed. Internal consistency in the current sample was very good $(\alpha=.907)$. As per Spitzer et al. (2006), cutoff scores of 5, 10, and 15 indicated mild, moderate, and severe anxiety, respectively.

Sports participation. Varsity sport (VS) was assessed by asking students if they participated in "competitive school sports teams that compete against other schools (e.g., junior varsity or varsity sports)" (yes, no, not available at my school). Outside of school sport (OSS) participation was determined by asking whether students participated in "league or team sports outside of school" (yes, no, not available where I live). For both VS and OSS, responses were expressed as binary codes. The response "yes" was coded as 1; "no" or "not available where I live" were combined and considered "no" and coded as 2. Both VS and OSS would be considered competitive sport; however, the level of competition may vary between sport groups. For example, in VS, the competitive level would be considered high, and athletes may be selected or deselected from a team based on skill. The competitive level of OSS could vary, from recreational athletes placed on teams through signing up for leagues, to highly competitive athletes selected for teams based on skill. The importance of this measure lies in the context of the sport (within or outside of school).

Covariates. Sleep, MVPA, screen time, and age were considered covariates. Sleep has been shown to have a bidirectional relationship with anxiety and depression (Shanahan, Copeland, Angold, Bondy, \& Costello, 2014). Sleep duration was assessed by asking students how much time they usually spend sleeping per day in hours (0-9) and minutes $(0,15,30$, and 45$)$. Similarly, physical activity, specifically MVPA, was controlled for given its aforementioned inverse relationship with anxiety and depression (Doré et al., 2016). Using previously validated measures, students were asked to indicate how many minutes of moderate (i.e., lower intensity activities "such as walking, biking to school, and recreational swimming") and hard (i.e., "jogging, team sports, fast dancing, jump-rope, and any other physical activities that increase your heart rate and make you breathe hard and sweat") physical activity they accumulated on each of the last 7 days to calculate a daily average (Leatherdale, Laxer, \& Faulkner, 2014; Wong, Leatherdale, \& Manske, 2006). Screen time has been shown to have a negative relationship with adolescent mental health (Twenge \& Campbell, 2018). Students were asked to identify, in hours and minutes, the length of time, each day, they spend on a screen. These measures were broken down into categories, including video/computer games, surfing the internet, texting/messaging/email, and watching/streaming TV shows/movies/videos. Total screen time was calculated by finding the sum of the length of time for all screen time categories. To 
control for school clustering, information regarding the students' schools was coded prior to data analysis; the data were then nested by school for analysis.

\section{Statistical Analysis}

Both CESD-R-10 and GAD-7 scores were expressed as continuous variables. Prior to hypothesis testing, the data were examined to ensure they upheld the assumptions for data analyses. Levene's tests of both CESD-R-10 and GAD-7 scores by VS status showed that the data violated the assumption of homogeneity of variance. Log-transformed scores upheld this assumption, but given that the results of the raw and transformed data were similar, raw scores were used due to their interpretability. The intraclass correlation coefficient (ICC) and design effect were calculated for CESD-R-10 and GAD-7 scores to assess the impact of shared variance in the nested data and the appropriateness of multilevel modeling (MLM). The ICCs were .02 and .03 for CESD-R-10 and GAD-7, respectively, and design effects were 10.94 and 18.53. Typically, ICCs closer to 1.0 and design effects over 2.0 are understood to be indicative of high levels of within-group variability and, therefore, require MLM, although it has been noted that values that do not reach these thresholds should still be analyzed by MLM (Huang, 2018; Tabachnick \& Fidell, 2019). Finally, average hours of sleep per day, MVPA per day, and total screen time per day were assessed as potential covariates. Sleep and total screen time significantly differed between the independent variable (varsity status; $p<.05$ ); as such, these variables were not used as covariates (Field, 2018).

The MLM procedures followed the hierarchical protocol of Field (2018), including: (a) a baseline model with the dependent variable scores (i.e., CESD-R10 or GAD-7) and factor of VS participation; (b) the addition of average daily MVPA as a covariate, followed by the inclusion of the Level 2 variable of school in terms of (c) random intercepts, and (d) random slopes; and, finally, (e) the potential interactions of the factors of sex and OSS. Each subsequent model was assessed via the change in -2 Log Likelihood. All analyses were conducted using IBM SPSS (version 25.0; IBM, 2020). The maximum likelihood method of extraction was employed.

\section{Results}

A total of 70,449 students provided information on VS participation status and completed either one or both the GAD-7 and CESD-R-10 scales. Table 1 summarizes demographic information for the total sample. Without considering level of sport participation, significant differences between sexes were detected for sleep and MVPA. Males had lower levels of sleep and higher levels of MVPA, as compared with females $(p<.001)$. Table 2 summarizes CESD-R-10 and GAD-7 scores by VS participation and sex. Males had significantly lower depression and anxiety scores, as compared with females $(p<.001)$. Approximately $13.3 \%$ and $18.3 \%$ of students participated in only VS and only OSS, respectively; $22.4 \%$ participated in both VS and OSS. Therefore, approximately 54\% of the sample participated in either VS or OSS. Varsity athletes had significantly lower scores for both depression and anxiety when compared with nonvarsity athletes, regardless of 
Table 1 Descriptive Statistics Among Secondary School Students in Year 7 (2018/2019) of the COMPASS Study

\begin{tabular}{|c|c|c|c|c|c|c|}
\hline \multirow[b]{2}{*}{ Characteristics } & \multicolumn{2}{|c|}{ Total sample } & \multicolumn{2}{|r|}{ Male } & \multicolumn{2}{|c|}{ Female } \\
\hline & $n$ & $\overline{\boldsymbol{x}}(\boldsymbol{S D})$ & $n$ & $\overline{\boldsymbol{x}}(\boldsymbol{S D})$ & $n$ & $\overline{\boldsymbol{x}}(\boldsymbol{S D})$ \\
\hline Age (years) & 70,077 & $15.2(1.5)$ & 34,728 & $15.2(1.5)$ & 35,038 & $15.1(1.5)$ \\
\hline MVPA/day (min) & 70,449 & $121.9(137.3)$ & 34,782 & $134.8(143.8)$ & 35,060 & $108.3(127.4)$ \\
\hline \multirow[t]{2}{*}{ Sleep duration $(\mathrm{hr})$} & 68,057 & $7.0(1.8)$ & 33,471 & $7.5(1.6)^{*}$ & 34,006 & $6.6(2.0)$ \\
\hline & $\mathbf{n}$ & $\%$ & $\mathbf{n}$ & $\%$ & $\mathbf{n}$ & $\%$ \\
\hline \multicolumn{7}{|l|}{ Province } \\
\hline Ontario & 28,892 & 41 & 14,335 & 41.2 & 14,264 & 40.7 \\
\hline Alberta & 3,129 & 4.4 & 1,532 & 4.4 & 1,567 & 4.5 \\
\hline British Columbia & 9,702 & 13.8 & 4,861 & 14.0 & 4,721 & 13.5 \\
\hline Quebec & 28,726 & 40.8 & 14,054 & 40.4 & 14,508 & 41.4 \\
\hline \multicolumn{7}{|l|}{ Sport participation } \\
\hline Only VS & 9,385 & 13.3 & 4,599 & 13.2 & 4,719 & 13.5 \\
\hline Only OSS & 12,872 & 18.3 & 6,379 & 18.4 & 6,408 & 18.3 \\
\hline None & 32,179 & 45.7 & 14,592 & 42.1 & 17,282 & 49.4 \\
\hline Both VS and OSS & 15,814 & 22.4 & 9,101 & 26.2 & 6,571 & 18.8 \\
\hline
\end{tabular}

Note $. \mathrm{n}=$ number of athletes; $x=$ average; COMPASS $=$ Cannabis use, Obesity, Mental health, Physical activity, Alcohol use, Smoking, and Sedentary behavior; MVPA = moderate to vigorous physical activity; VS = varsity sport; OSS = outside school sport.

*Significantly different from females $(p<.001)$.

Table 2 CESD-R-10 and GAD-7 Scores by Sex and Sport Participation Status Among Secondary School Students in Year 7 (2018/2019) of the COMPASS Study

\begin{tabular}{lccccc}
\hline \multirow{2}{*}{ Sex and sport participation } & \multicolumn{2}{c}{ CESD-R-10 } & & \multicolumn{2}{c}{ GAD-7 } \\
\cline { 2 - 3 } \cline { 5 - 6 } & $\boldsymbol{n}$ & $\overline{\boldsymbol{x}}(\boldsymbol{S D})$ & & $\boldsymbol{n}$ & $\overline{\boldsymbol{x}}(\boldsymbol{S D})$ \\
\hline Total sample & 63,280 & $8.79(6.04)$ & & 67,850 & $6.15(5.58)$ \\
$\quad$ Varsity & 22,641 & $8.01(5.64)^{*}$ & & 24,331 & $5.50(5.28)^{*}$ \\
$\quad$ Not varsity & 40,463 & $9.23(6.21)$ & & 43,323 & $6.51(5.72)$ \\
Males & 31,080 & $7.38(5.29)^{* *}$ & & 33,692 & $4.58(4.90)^{* *}$ \\
$\quad$ Varsity & 12,211 & $6.77(4.83)^{*}$ & & 13,282 & $4.08(4.50)^{*}$ \\
Not varsity & 18,765 & $7.77(5.53)$ & & 20,295 & $4.92(5.13)$ \\
Females & 31,665 & $10.14(.38)$ & & 33,579 & $7.69(5.76)$ \\
$\quad$ Varsity & 10,240 & $9.46(6.14)^{*}$ & & 10,851 & $7.23(5.61)^{*}$ \\
$\quad$ Not varsity & 21,355 & $10.47(6.47)$ & & 22,650 & $7.91(5.82)$ \\
\hline
\end{tabular}

Note. $\mathrm{n}=$ number of athletes; $\mathrm{x}=$ average; CESD-R-10 $=$ the 10 -item Center for Epidemiologic Studies Depression scale-Revised; GAD-7 = 7-item Generalized Anxiety Disorder scale; COMPASS = Cannabis use, Obesity, Mental health, Physical activity, Alcohol use, Smoking, and Sedentary behavior.

${ }^{*}$ Significant difference $(p<.001)$ as compared with nonvarsity athletes. ${ }^{* *}$ Significant difference $(p<.001)$ from females. 
sex $(p<.001)$. Table 3 further breaks down the analysis into subgroups, showing CESD-R-10 and GAD-7 scores for VS and OSS participants and nonparticipants. In most cases, students who participated in VS and OSS had significantly lower scores than students who only participated in VS $(p<.001)$. This relationship was seen in all subgroups with the exception of GAD-7 scores in female varsity athletes.

For both depression and anxiety scores, the baseline models comprised a significant effect for VS and significant variance of slopes and intercept; each subsequent model was a significant improvement on the previous model. The ultimate result of each analysis was a significant three-way interaction between VS participation, sex, and OSS participation on the dependent variables (Figures 1 and 2). Specifically, the model for depression revealed a significant effect for the covariate of MVPA, $t(1,62321.62)=4.71, p<.001$, and a three-way interaction

\section{Table 3 CESD-R-10 and GAD-7 Scores for All Sport Participation Subgroups Among Secondary School Students in Year 7 (2018/2019) of the COMPASS Study}

\begin{tabular}{|c|c|c|c|c|}
\hline \multirow[b]{2}{*}{ Sex and sport participation } & \multicolumn{2}{|c|}{ CESD-R-10 } & \multicolumn{2}{|c|}{ GAD-7 } \\
\hline & $n$ & $\overline{\boldsymbol{X}}(\boldsymbol{S D})$ & $n$ & $\overline{\boldsymbol{X}}(\boldsymbol{S D})$ \\
\hline \multicolumn{5}{|l|}{ Varsity } \\
\hline \multicolumn{5}{|l|}{ Total } \\
\hline OSS & 14,171 & $7.70(5.50)^{\#}$ & 15,231 & $5.30(5.30)^{\#}$ \\
\hline No OSS & 8417 & $8.50(5.80)$ & 9042 & $5.80(5.30)$ \\
\hline \multicolumn{5}{|l|}{ Male } \\
\hline OSS & 8,088 & $6.58(4.75)^{\#}$ & 8,796 & $3.95(4.46)^{\#}$ \\
\hline No OSS & 4,091 & $7.12(4.98)$ & 4,451 & $4.35(4.56)$ \\
\hline \multicolumn{5}{|l|}{ Female } \\
\hline OSS & 5,950 & $9.27(6.12)^{\#}$ & 6,303 & $7.23(5.66)$ \\
\hline No OSS & 4,270 & $9.73(6.16)$ & 4,526 & $7.24(5.55)$ \\
\hline \multicolumn{5}{|l|}{ Nonvarsity } \\
\hline \multicolumn{5}{|l|}{ Total } \\
\hline OSS & 11,519 & $8.10(5.90)^{\#}$ & 12,380 & $5.70(5.40)^{\#}$ \\
\hline No OSS & 28,840 & $9.70(6.30)$ & 30,818 & $6.80(5.80)$ \\
\hline \multicolumn{5}{|l|}{ Male } \\
\hline OSS & 5,654 & $6.78(5.01)^{\#}$ & 6,174 & $4.17(4.69)^{\#}$ \\
\hline No OSS & 13,053 & $8.20(5.69)$ & 14,053 & $5.24(5.27)$ \\
\hline \multicolumn{5}{|l|}{ Female } \\
\hline OSS & 5,785 & $9.44(6.28)^{\#}$ & 6,125 & $7.24(5.61)^{\#}$ \\
\hline No OSS & 15,529 & $10.85(6.49)$ & 16,474 & $8.16(5.86)$ \\
\hline
\end{tabular}

Note. $\mathrm{n}=$ number of athletes; $x=$ average; CESD-R-10 $=$ the 10-item Center for Epidemiologic Studies Depression scale-Revised; GAD-7 = 7-item Generalized Anxiety Disorder scale; COMPASS $=$ Cannabis use, Obesity, Mental health, Physical activity, Alcohol use, Smoking, and Sedentary behavior; OSS = Outside School Sport.

\#Significant difference $(p<.001)$ from no OSS. 


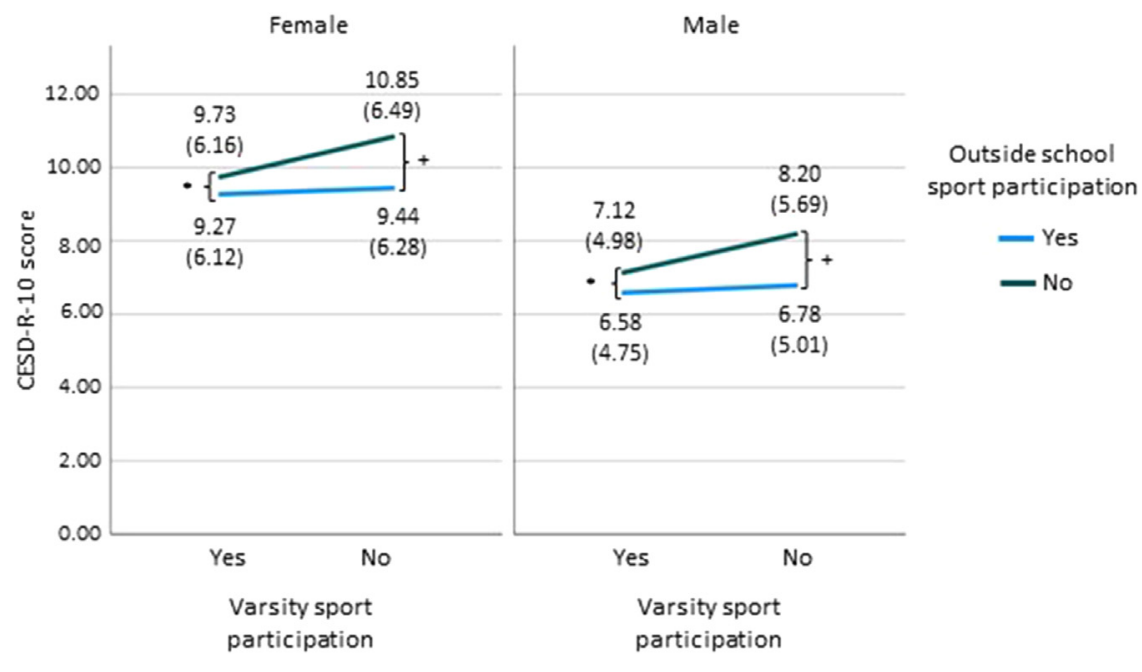

Figure 1 - Depressive symptoms (CESD-R-10) by sex and sport participation among youth participating in Year 7 (2018/2019) of the COMPASS study. *Significant difference $(p<.001)$ in CESD scores between varsity sport participants who also participated in outside school sport (VS + OSS) and those who participated in only varsity sport (VS). ${ }^{+}$Significant difference $(p<.001)$ in CESD scores between those students who do not participate in varsity sport but do participate in OSS (OSS) and those who participate in neither VS or OSS (no sport). CESD-R-10 =10-item Center for Epidemiologic Studies Depression scaleRevised; COMPASS = Cannabis use, Obesity, Mental health, Physical activity, Alcohol use, Smoking, and Sedentary behavior.

between sex, OSS, and VS on depression $t(1,61378.57)=2.95, p<.05$. Furthermore, the variances for both the intercept and slope in the model varied significantly, indicating that both parameters varied by school. Similarly, for anxiety, the effect for both the covariate $t(1,66784.08]=2.28, p<.05$, and interaction $t(1$, $65413.8)=5.26, p<.001$, were significant, and, again, slope and intercept varied significantly within the model.

These significant interactions were analyzed by examining two-way interactions and then main effects, within designated factors. Specifically, independent models for males and females revealed a significant interaction for VS and OSS participation on depression and anxiety scores (Figures 1 and $2 ; p<.05$ ). These significant two-way interactions were followed by separate samples according to sex and OSS status to see if there was a significant effect for VS participation in each of these four groups on depression and anxiety. In other words, the analysis proceeded to MLM models for the effect of VS participation on depression and anxiety scores for four samples: males who did, and did not, participate in OSS and females who did, and did not, participate in OSS. The results of these models are given in Table 4; results show the effect of VS on CESD-R-10 or GAD-7, after statistically controlling for average MVPA. In each of the four independent models for both depression and anxiety, VS had a significant effect after statistically controlling for the effect of MVPA $(p<.05)$. However, in 6 of the 8 models, the 


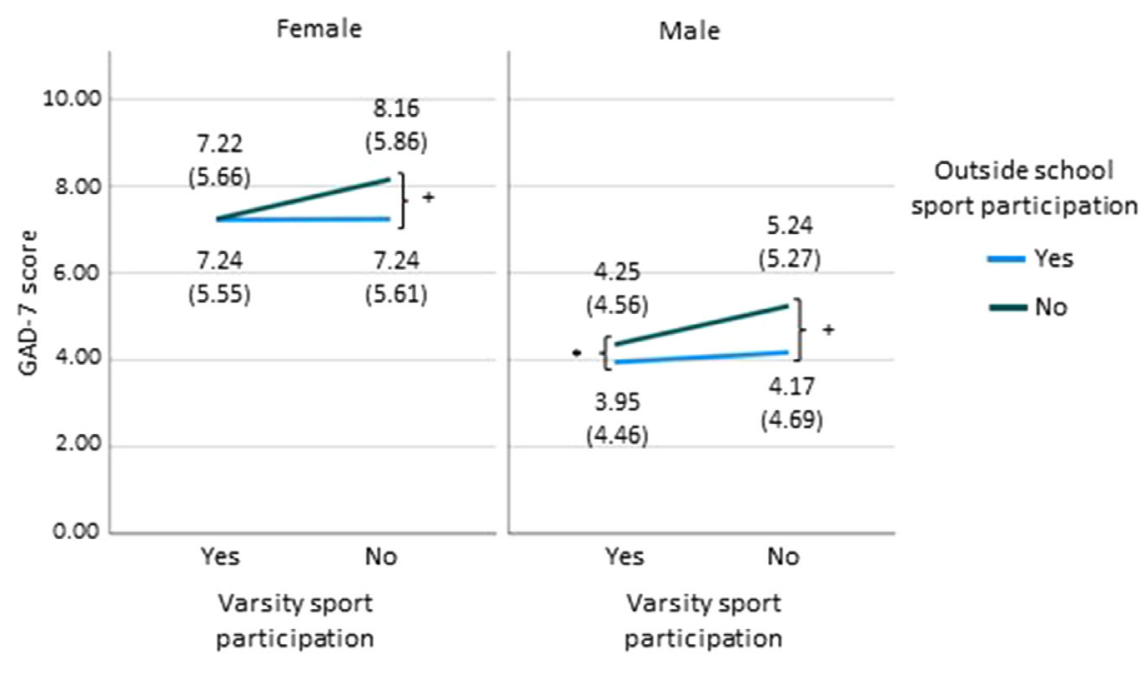

Figure 2 - Anxiety symptoms (GAD-7) by sex and sport participation among youth participating in Year $7(2018 / 2019)$ of the COMPASS study. ${ }^{*}$ Significant difference $(p<$ $.001)$ in GAD-7 scores between varsity sport participants who also participated in outside school sport (VS + OSS) and those who participated in only varsity sport (VS). ${ }^{+}$Significant difference $(p<.001)$ in GAD-7 scores between those students who do not participate in varsity sport but do participate in OSS (OSS) and those who participate in neither VS or OSS (no sport). GAD-7 = 7-item Generalized Anxiety Disorder scale; COMPASS = Cannabis use, Obesity, Mental health, Physical activity, Alcohol use, Smoking, and Sedentary behavior.

variance for slope and intercept was not significant. This result indicates that, although the three-way models varied significantly by school, once we examine these interactions in individual analyses by groups of sex and OSS conditions, the significant effect of VS on mental health is not nested within schools.

\section{Discussion}

The purpose of this study was to explore the relationship between athletic status and symptoms of depression and anxiety in a large sample of Canadian high school students. Just over half of the sample (54\%) participated in organized sport. A recent report found that, based on self-reported data, $66 \%$ of students, Grades 6-10, participate in individual and/or team sport (ParticipACTION, 2020). The slightly lower percentage of involvement in the current sample is expected as sport participation drops with age, especially during the transition to high school (Eime, Harvey, Charity, \& Payne, 2016; Zimmerman-Sloutskis, Wanner, Zimmermann, \& Martin, 2010). Our results support earlier work, concluding that sport participation has beneficial effect on adolescent mental health (Breist $\varnothing 1$ et al., 2017; Doré et al., 2016; Jewett et al., 2014; McMahon et al., 2017; Sabiston et al., 2016). Results indicated a significant association between VS participation and symptoms of depression and anxiety in the sampled adolescents. In both males and females, 


\section{Table 4 Summary of Multilevel Modeling Exploring the Effects of Varsity Sport Participation on CESD-R-10 and GAD-7 Scores}

\begin{tabular}{|c|c|c|c|c|c|c|}
\hline \multirow[b]{2}{*}{ DV } & \multirow[b]{2}{*}{ Model } & \multirow[b]{2}{*}{$F(d f)$} & \multicolumn{2}{|c|}{ Intercept } & \multicolumn{2}{|c|}{ Slope } \\
\hline & & & Estimate & Variance & Estimate & Variance \\
\hline \multirow[t]{4}{*}{$\begin{array}{l}\text { CESD- } \\
\text { R-10 }\end{array}$} & $\begin{array}{l}\text { Female } \\
\text { OSS }\end{array}$ & $\begin{array}{c}10.53^{*} \\
(1,102.22)\end{array}$ & $8.77 *$ & 0.49 & $0.40 *$ & 0.19 \\
\hline & $\begin{array}{l}\text { Female } \\
\text { no OSS }\end{array}$ & $\begin{array}{c}78.26^{*} \\
(1,189.67)\end{array}$ & $8.77 *$ & 0.43 & $1.09 *$ & 0.34 \\
\hline & $\begin{array}{l}\text { Male } \\
\text { OSS }\end{array}$ & $\begin{array}{c}13.09 * \\
(1,70.37)\end{array}$ & $6.25^{*}$ & 0.23 & $0.32 *$ & 0.05 \\
\hline & $\begin{array}{l}\text { Male } \\
\text { no OSS }\end{array}$ & $\begin{array}{c}81.14^{*} \\
(1,107.85)\end{array}$ & $6.30 *$ & $1.22 *$ & $0.99 *$ & 0.21 \\
\hline \multirow[t]{4}{*}{ GAD-7 } & $\begin{array}{l}\text { Female } \\
\text { OSS }\end{array}$ & $\begin{array}{c}9.54 * \\
(1,90.09)\end{array}$ & $6.81 *$ & 1.07 & $0.36^{*}$ & 0.30 \\
\hline & $\begin{array}{l}\text { Female } \\
\text { no OSS }\end{array}$ & $\begin{array}{c}68.80^{*} \\
(1,71.55)\end{array}$ & $6.67^{*}$ & 1.17 & $0.82^{*}$ & 0.05 \\
\hline & $\begin{array}{l}\text { Male } \\
\text { OSS }\end{array}$ & $\begin{array}{c}9.99^{*} \\
(1,104.55)\end{array}$ & $3.66^{*}$ & $0.58^{*}$ & $0.30^{*}$ & $0.33^{*}$ \\
\hline & $\begin{array}{l}\text { Male } \\
\text { no OSS }\end{array}$ & $\begin{array}{c}77.64^{*} \\
(1,103.99)\end{array}$ & $3.63^{*}$ & 0.69 & $0.86^{*}$ & 0.18 \\
\hline
\end{tabular}

Note. CESD-R-10 = 10-item Center for Epidemiologic Studies Depression scale-Revised; GAD-7 = 7-item Generalized Anxiety Disorder scale; DV = dependent variable; OSS = Outside School Sport. $* p<.05$.

those who participated in VS had lower anxiety and depression scores than those who did not participate in VS. This effect held true regardless of participation status in OSS; however, the effect was stronger among those who participated in both VS and OSS. Such results suggest an additive effect of sport participation, in that more sport participation is associated with lower depression and anxiety scores. Although the beneficial effect of VS participation was seen across sexes, the relationship between VS participation and anxiety and depression scores was stronger in males.

This study reported a positive additive effect of sport participation on symptoms of depression and anxiety; earlier research on adolescent extracurricular involvement supports this claim. More involvement in organized activities is associated with positive youth development (Busseri, Rose-Krasnor, Willoughby, \& Chalmers, 2006; Linver, Roth, \& Brooks-Gun, 2009; Zarrett et al., 2009), future risk behaviors, interpersonal functioning (Busseri et al., 2006), perceived value, usefulness, and safety (Forneris, Camiré, \& Williamson, 2015), as well as depression and contribution to the community (Zarrett et al., 2009). It has been suggested that the breadth (number) of activities that one participates in may have a unique effect on positive outcomes due to the increased opportunity for developmental advancement (Busseri et al., 2006; Fredricks \& Eccles, 2006). Research has found that when youth participate in many activities within different contexts, they have more opportunities to grow. For instance, if one particular activity or context does not provide a specific "feature" needed for development, they can draw on 
the others to fill that void (Baltes, 1997; Baltes, Lindenberger, \& Staudinger, 1999; Busseri et al., 2006; Fredricks \& Eccles, 2006). Therefore, it is possible that students participating in both VS and OSS had lower depression and anxiety symptoms, as they were able to "draw" from both contexts to optimize positive development.

The current study found beneficial additive effects of sport participation on symptoms of anxiety and depression. However, some researchers have voiced concerns about how parental pressures to participate, and the over scheduling of such activities, may influence adolescent mental health (Randall \& Bohert, 2009; Zarrett et al., 2009). Mahoney and colleagues (Mahoney, Harris, \& Eccles, 2006; Mahoney \& Vest, 2012) reported that most sport participation is intrinsically motivated and that there is little support for the "over-scheduling hypothesis." While adolescents may not be "over-scheduled," there are still recommendations in place to reduce the risk of injury, burnout, and attrition caused by high frequency/ high rate of participation in sporting activities. Such recommendations include a maximum of 5 days per week of sport participation (Brenner \& The Council on Sports Medicine and Fitness, 2016), limiting hours per week of participation to the age of the adolescent in years (Jayanthi, LaBella, Fischer, Pasulka, \& Dugas, 2015) and less than $16 \mathrm{hr}$ per week (Rose, Emery, \& Meeuwisse, 2008). When looking specifically at participation frequency and adolescent well-being, Merglen, Flatz, Belanger, Michaud, and Suris (2013) found that adolescents who participated in sport less than $14 \mathrm{hr}$ per week maintained the beneficial effects of sport participation. Future researchers should consider collecting frequency-specific data (time per day and/or time per week) to explore any mediating effects of participation frequency on sport and mental health.

Researchers have explored the effects of young athletes dedicating their time to one sport and avoiding participation in others. In addition to a number of negative physical effects, there is also evidence to suggest that sport specialization can be an emotional burden on youth (Smucny, Parikh, \& Pandya, 2015). This study found that those students who participated in both VS and OSS scored lower on depression and anxiety symptom scales. However, the current study did not explore if the VS and OSS activities were the same. Research has found that early specialization in one sport can lead to burnout, social isolation, overdependence, arrested behavioral development, and socially maladaptive behaviors (Malina, 2009, 2010). Conversely, Dahab, Potter, Provance, Albright, and Howell (2019) found no differences in quality of life or depression scores between those high school athletes who were classified, by the authors, as low, medium, or highly specialized into one sport. However, in this study, the authors advise that the results should be interpreted with caution due to selection bias and an imbalanced sample (more low specialization than high). As such, future research should aim to collect sport-specific data, such as what sport(s) is/are played at which level (VS or OSS). Gathering such information could help explore the relationship of both specialization and context on mental health.

Previous research has found mixed results when determining the potential influence of MVPA on the relationship between sport and mental health in nonclinical populations (Bell, Audrey, Gunnell, Cooper, \& Campbell, 2019; Doré et al., 2016, 2020; Siefken, Junge, \& Laemmle, 2019). The current study found MVPA as a significant covariate; as such, results suggest that both VS and 
OSS are forms of physical activity associated with improved mental health status regardless of MVPA. This study therefore supports research that has theorized that the context of physical activity is what is particularly beneficial, not necessarily the intensity of the activity itself (Brunet et al., 2014; Doré et al., 2016; Evans et al., 2017; Lubans et al., 2016). The impact of context on the relationship between physical activity and mental health may be based on the ability of that context to satisfy basic psychological needs (autonomy, competence, and relatedness; Bartholomew, Ntoumanis, Ryan, \& Thøgersen-Ntoumani, 2011; Standage, Gillison, Ntoumanis, \& Treasure, 2012). According to the Positive Youth Development model (Fraser-Thomas, Côté, \& Deakin, 2005), greater benefits of mental health are seen when physical activity promotes positive psychological and social environments through supportive social relationships. It is therefore possible that sport participation, both within and outside of school, fulfill the three psychological needs and provide social support and acceptance, thereby positively influencing symptoms of depression and anxiety in youth. Future prospective research should explore these mechanisms in the relationships found.

The significant effect of sex on the relationship between sport and mental health in the current study supports earlier evidence (Guddal et al., 2019; Jewett et al., 2014). In males, depression and anxiety scores were significantly different between VS and non-VS participants. However, when comparing female VS participants to nonparticipants, varsity athletes had significantly lower depression scores, but no significant differences were found in anxiety scores. It is possible that the insignificant difference between VS and non-VS females is due to the high levels of anxiety found in females within the general (Kessler et al., 2012) and athletic populations (Dolenc, 2015; Pluhar et al., 2019; Yang et al., 2007). As anxiety levels are higher in females to begin with, it may be that participation in VS does not significantly impact anxiety symptoms. In addition, in males, the analysis revealed a significant difference in the variance of intercept and slope. The interpretation of the ICC revealed that $2 \%$ and $3 \%$ of variance for depression and anxiety scores was explained at the school level. This could indicate a potential contextual influence on mental health, in that pressures unique to individual schools could influence general levels of male varsity athlete anxiety and depression and/or could influence the effects of VS participation on anxiety.

Using a large and diverse sample of Canadian high school students, this study suggests that sport participation should be promoted for the prevention and management of adolescent mental illness. With such a sample, we can be more confident in generalizing our novel and valuable results to the Canadian adolescent population. Potential additive effects suggest students should be supported in participating in multiple sporting opportunities to increase the benefits of sport participation on internalizing symptoms. These conclusions should be interpreted with the following limitations in mind. First, cross-sectional data cannot infer causation. It is plausible that youth with fewer symptoms of depression and anxiety are more likely to participate in sport. Future research using prospective data should be used to address this limitation and establish the direction of the relationship between sport participation, depression, and anxiety symptoms. Second, the measures used in the current study do not differentiate between team and individual sport participation, or whether OSS was competitive or recreational in nature. The impact of both sport type and competition level on the relationship between sport 
participation and mental health has been debated (Breistøl et al., 2017; Doré et al., 2016; McMahon et al., 2017). Third, although excluding sleep and screen as covariates were justified (Field, 2018), this should be considered a limitation. These variables have been shown to impact adolescent mental health (Shanahan et al., 2014; Twenge \& Campbell, 2018), therefore, it is possible that the inclusion of these factors may have influenced results. In addition, the analysis did not control for frequency (hours per week) of participation in neither VS nor OSS. Similarly, the effect of additional extracurricular activities (e.g., art, academic, cultural clubs or volunteering) on depression and anxiety symptoms were not considered in this analysis. Both frequency (Eime et al., 2013; Panza et al., 2020) and involvement in other types of activities (Oberle et al., 2020) have been shown to impact adolescent mental health. As such, the current study may have missed a potential effect of these variables on the mental health of students.

\section{Acknowledgments}

The authors would like to thank the schools, school boards, and students that have participated in the COMPASS study, and all COMPASS team members and staff. The COMPASS study has been supported by a bridge grant from the CIHR Institute of Nutrition, Metabolism, and Diabetes (INMD) through the "Obesity-Interventions to Prevent or Treat" priority funding awards (OOP-110788; awarded to S.T. Leatherdale), an operating grant from the CIHR Institute of Population and Public Health (IPPH) (MOP-114875; awarded to S.T. Leatherdale), a CIHR Project Grant (PJT-148562; awarded to S.T. Leatherdale), a CIHR Project Grant (PJT-159693; awarded to K.A. Patte), and by a research funding arrangement with Health Canada (number 1617-HQ-000012; awarded to S.T. Leatherdale). The COMPASS Mental Health Pilot Study was funded by a CIHR bridge grant (PJT-149092; awarded to K.A. Patte/S.T. Leatherdale). None of the authors have any conflicts of interest to declare.

\section{References}

Andresen, E.M., Malmgren, J.A., Carter, W.B., \& Patrick, D.L. (1994). Screening for depression in well older adults: Evaluation of a short form of the CES-D. American Journal of Preventative Medicine, 10(2), 77-84. PubMed ID: 8037935

Archer, G., Kuh, D., Hotopf, M., Stafford, M., \& Richards, M. (2018). Adolescent affective symptoms and mortality. The British Journal of Psychiatry, 213(1), 419-424. PubMed ID: 29804549 doi:10.1192/bjp.2018.90

Auerbach, R.P., Kim, J.C., Chango, J.M., Spiro, W.J., Ch, C., Gold, J., ... Nock, M.K. (2014). Adolescent nonsuicidal self-injury: Examining the role of child abuse, comorbidity, and disinhibition. Psychiatry Research, 220(1-2), 579-584. PubMed ID: 25095754 doi:10.1016/j.psychres.2014.07.027

Auerbach, R.P., Tsai, B., \& Abela, J.R.Z. (2010). Temporal relationships among depressive symptoms, risky behavior engagement, perceived control, and gender in a sample of adolescents. Journal of Research on Adolescence, 20(3), 726-747.

Baltes, P.B. (1997). On the incomplete architecture of human ontogeny. Selection, optimization, and compensation as foundation of developmental theory. American Psychologist, 52(4), 366-380. PubMed ID: 9109347 doi:10.1037//0003-066x.52.4.366

Baltes, P.B., Lindenberger, U., \& Staudinger, U.M. (1999). Life-span theory in developmental psychology. In W. Damon \& R.M. Lerner (Eds.), Handbook of child 
psychology: Theoretical models of human development (5th ed., Vols. 1). New York, NY: John Wiley \& Sons.

Barth Vedøy, I., Anderssen, S.A., Tjomsland, H.E., Skulberg, K.R., \& Thurston, M. (2020). Physical activity, mental health and academic achievement: A cross-sectional study of Norwegian adolescents. Mental Health and Physical Activity, 18, 100322. doi:10. 1016/j.mhpa.2020.100322

Bartholomew, K.L., Ntoumanis, N., Ryan, R.M., \& Thøgersen-Ntoumani, C. (2011). Psychological need thwarting in the sport context: Assessing the darker side of athletic experience. Journal of Sport and Exercise Psychology, 33(1), 75-102. PubMed ID: 21451172 doi: 10.1123 jsep.33.1.75

Bell, S.L., Audrey, S., Gunnell, D., Cooper, A., \& Campbell, R. (2019). The relationship between physical activity, mental wellbeing and symptoms of mental health disorder in adolescents: A cohort study. International Journal of Behavioral Nutrition and Physical Activity, 16(1), 138. PubMed ID: 31878935 doi:10.1186/s12966-0190901-7

Biddle, S.J.H., Ciaccioni, S., Thomas, G., \& Vergeer, I. (2019). Physical activity and mental health in children and adolescents: An updated review of reviews and an analysis of causality. Psychology of Sport and Exercise, 42, 146-155.

Bradley, K.L., Bagnell, A.L., \& Brannen, C.L. (2010). Factorial validity of the center for epidemiological studies depression 10 in adolescents. Issues in Mental Health Nursing, 31(6), 408-412. PubMed ID: 20450343 doi:10.3109/01612840903484105

Breistøl, S., Clench-Aas, J., Van Roy, B., \& Kjærsti Raanaas, R. (2017). Association between participating in noncompetitive or competitive sports and mental health among adolescents-A Norwegian population-based cross-sectional study. Scandinavian Journal of Child and Adolescent Psychiatry and Psychology, 5(1), 28-38. doi: 10.21307/sjcapp-2017-003

Brenner, J.S., \& The Council on Sports Medicine and Fitness (AAP). (2016). Sports specialization and intensive training in young athletes. Pediatrics, $138(3)$, e20162148. PubMed ID: 27573090 doi:10.1542/peds.2016-2148

Brière, F.N., Yale-Soulière, G., Gonzalez-Sicilia, D., Harbec, M.-J., Morizot, J., Janosz, M., \& Pagani, L.S. (2018). Prospective associations between sport participation and psychological adjustment in adolescents. Journal of Epidemiology and Community Health, 72(7), 575. PubMed ID: 29540466 doi:10.1136/jech-2017-209656

Brunet, J., Sabiston, C.M., O’Loughlin, E., Chaiton, M., Low, N.C.P., \& O'Loughlin, J.L. (2014). Symptoms of depression are longitudinally associated with sedentary behaviors among young men but not among young women. Preventative Medicine, 60, 16-20. PubMed ID: 24333606 doi:10.1016/j.ypmed.2013.12.003

Busseri, M.A., Rose-Krasnor, L., Willoughby, T., \& Chalmers, H. (2006). A longitudinal examination of breadth and intensity of youth activity involvement and successful development. Developmental Psychology, 42(6), 1313-1326. PubMed ID: 17087563 doi:10.1037/0012-1649.42.6.1313

Carek, P.J., Laibstain, S.E., \& Carek, S.M. (2011). Exercise for the treatment of depression and anxiety. International Journal of Psychiatry in Medicine, 41(1), 15-28. PubMed ID: 21495519 doi:10.2190/PM.41.1.c

Chartier, M., Vander Stoep, A., McCauley, E., Herting, J.R., Tracy, M., \& Lymp, J. (2008). Passive versus active parental consent: Implications for the ability of school-based depression screening to reach youth at risk. Journal of School Health, 78(3), 157-186. PubMed ID: 18307611 doi:10.1111/j.1746-1561.2007.00278.x

Clayborne, Z.M., Varin, M., \& Colman, I. (2019). Systematic review and meta-analysis: Adolescent depression and long-term psychosocial outcomes. Journal of the American Academy of Child and Adolescent Psychiatry, 58(1), 72-79. PubMed ID: 30577941 doi:10.1016/j.jaac.2018.07.896 
Dahab, K., Potter, M.N., Provance, A., Albright, J., \& Howell, D.R. (2019). Sport specialization, club sport participation, quality of life, and injury history among high school athletes. Journal of Athletic Training, 54(10), 1061-1066. PubMed ID: 31633407 doi:10.4085/1062-6050-361-18

Dale, L.P., Vanderloo, L., Moore, S., \& Faulkner, G. (2019). Physical activity and depression, anxiety, and self-esteem in children and youth: An umbrella systematic review. Mental Health and Physical Activity, 16, 66-79.

Dolenc, P. (2015). Anxiety, self-esteem, and coping with stress in secondary school students in relation to involvement in organized sports. De Gruyter OPEN, 54(3), 222-229. PubMed ID: 27646730 doi:10.1515/sjph-2015-0031

Doré, I., O’Loughlin, J.L., Beauchamp, G., Martineau, M., \& Fournier, L. (2016). Volume and social context of physical activity in association with mental health, anxiety and depression among youth. Preventative Medicine, 91, 344-350. PubMed ID: 27609745 doi:10.1016/j.ypmed.2016.09.006

Doré, I., O’Loughlin, J.L., Schnitzer, M.E., Datta, G.D., \& Fournier, L. (2018). The longitudinal association between the context of physical activity and mental health in early adulthood. Mental Health and Physical Activity, 14, 121-130.

Doré, I., Sylvester, B., Sabiston, C., Sylvestre, M.-P., O’Loughlin, J., Brunet, J., \& Bélanger, M. (2020). Mechanisms underpinning the association between physical activity and mental health in adolescence: A 6-year study. International Journal of Behavioral Nutrition and Physical Activity, 17(1), 9. PubMed ID: 32005251 doi:10.1186/s12966020-0911-5

Eime, R.M., Harvey, J.T., Brown, W.J., \& Payne, W.R. (2010). Does sports club participation contribute to health-related quality of life? Medicine \& Science in Sports \& Exercise, 42(5), 1022-1028. PubMed ID: 19996991 doi:10.1249/MSS.0b013e3181c3adaa

Eime, R.M., Harvey, J.T., Charity, M.J., \& Payne, W.R. (2016). Population levels of sport participation: Implications for sport policy. BMC Public Health, 16(1), 752. PubMed ID: 27506922 doi:10.1186/s12889-016-3463-5

Eime, R.M., Young, J.A., Harvey, J.T., Charity, M.J., \& Payne, W.R. (2013). A systematic review of the psychological and social benefits of participation in sport for children and adolescents: Informing development of a conceptual model of health through sport. The International Journal of Behavioral Nutrition and Physical Activity, 10(1), 98. PubMed ID: 23945179 doi:10.1186/1479-5868-10-98

Evans, B.M., Allan, V., Erickson, K., Martin, L.J., Budziszewski, R., \& Côté, J. (2017). Are all sport actitities equal? A systemtic review of how youth psychosocial experiences vary across differing sport activities. Journal of Sports Medicine, 51(3), 169-176. PubMed ID: 27986759 doi:10.1136/bjsports-2016-096725

Fergusson, D.M., Boden, J.M., \& Horwood, L.J. (2007). Recurrence of major depression in adolescence and early adulthood, and later mental health, educational and economic outcomes. British Journal of Psychiatry, 191(4), 335-342. PubMed ID: 17906244 doi:10.1192/bjp.bp.107.036079

Fergusson, D.M., \& Woodward, L.J. (2002). Mental health, educational, and social role outcomes of adolescents with depression. JAMA Psychiatry, 59(3), 225-231. PubMed ID: 11879160 doi:10.1001/archpsyc.59.3.225

Field, A. (2018). Discovering statistics using IBM SPSS statistics (5th ed.). London, UK: SAGE.

Forneris, T., Camiré, M., \& Williamson, R. (2015). Extracurricular activity participation and the acquisition of developmental assets: Differences between involved and noninvolved Canadian high school students. Applied Developmental Science, 19(1), 47-55.

Fraser-Thomas, J.L., Côté, J., \& Deakin, J. (2005). Youth sport programs: An avenue to foster positive youth development. Physical Education and Sport Pedagogy, 1(1), $19-40$. 
Fredricks, J.A., \& Eccles, J.S. (2006). Is extracurricular participation associated with beneficial outcomes? Concurrent and longitudinal relations. Developmental Psychology, 42(4), 698-713. PubMed ID: 16802902 doi:10.1037/0012-1649.42.4.698

Garnefski, N., \& Kraaij, V. (2018). Specificity of relations between adolescents' cognitive emotion regulation strategies and symptoms of depression and anxiety. Cognition and Emotion, 32(7), 1401-1408. PubMed ID: 27648495 doi:10.1080/02699931.2016. 1232698

Gaudlitz, K., von Lindenberger, B.-L., Zschucke, E., \& Ströhle, A. (2013). Mechanisms underlying the relationship between physical activity and anxiety: Human daata. In P. Ekkekakis (Ed.), Routledge handbook of physical activity and mental health (pp. 117129). London, UK: Routledge.

Guddal, M.H., Strensland, S.Ø., Småstuen, M.C., Johnsen, M.B., Zwart, J.-A., \& Storheim, K. (2019). Physical activity and sport participation among adolescents: Associations with mental health in different age groups. Results from the Young-HUNT study: A cross-sectional survey. BMJ Open, 9(9), e028555. PubMed ID: 31488476 doi:10.1136/ bmjopen-2018-028555

Haroz, E.E., Ybarra, M.L., \& Eaton, W.W. (2014). Psychometric evaluation of a self-report scale to measure adolescent depression: The CESDR-10 in two national adolescent samples in the United States. Journal of Affective Disorders, 158, 154-160. PubMed ID: 24655780 doi:10.1016/j.jad.2014.02.009

Huang, F.L. (2018). Multilevel modeling myths. School of Psychology Quarterly, 33, 492499. PubMed ID: 30070555 doi:10.1037/spq0000272

IBM. (2020). SPSS Statistical Software Version 26 (Version 26) [Computer software]. Retrieved from https://www.ibm.com/analytics/spss-statistics-software?lnk=STW_US_ STESCH\&lnk2=trial_SPSS\&pexp=def\&psrc=none\&mhsrc=ibmsearch_a\&mhq=spss

Jayanthi, N.A., LaBella, C.R., Fischer, D., Pasulka, J., \& Dugas, L.R. (2015). Sportsspecialized intensive training and the risk of injury in young athletes: A clinical casecontrol study. American Journal of Sports Medicine, 43(4), 794-801. PubMed ID: 25646361 doi: $10.1177 / 0363546514567298$

Jewett, R., Sabiston, C.M., Brunet, J., O’Loughlin, E.K., Scarapicchia, T., \& O’Loughlin, J. (2014). School sport participation during adolescence and mental health in early adulthood. Journal of Adolescent Health, 55(5), 640-644. PubMed ID: 24928804 doi:10.1016/j.jadohealth.2014.04.018

Kessler, R.C., Avenevoli, S., Costello, J., Georgiades, K., Greif Green, J., Gruber, M.J., . . . Merikangas, K.R. (2012). Prevalence, persistence, and sociodemographic correlates of DSM-IV disorders in the National Comorbidity Survey replication adolescent supplement. Archives of General Psychiatry, 69(4), 372-380. PubMed ID: 22147808 doi:10. 1001/archgenpsychiatry.2011.160

Leatherdale, S., Brown, S.K., Carson, V., Childs, R.A., Dubin, J.-A., Elliott, S.J. , . . . Thompson-Haile, A. (2014). The COMPASS study: A longitudinal hierarchical research platform for evaluating natural experiments related to changes in school-level programs, policies and built environment resources. BMC Public Health, 14(331), 1-7.

Leatherdale, S., Laxer, R.E., \& Faulkner, G. (2014). Reliability and validity of the PA and sedentary behaviour measures in the COMPASS study. COMPASS Technical Report Series, 2(1). Waterloo, Ontario: University of Waterloo. www.compass.uwaterloo.ca

Linver, M.R., Roth, J.L., \& Brooks-Gun, J. (2009). Patterns of adolescents' participation in organized activities: Are sports best when combined with other activities? Developmental Psychology, 45(2), 354-367. PubMed ID: 19271824 doi:10.1037/a0014133

Lubans, D., Richards, J., Hillman, C., Faulkner, G., Beauchamp, M., Nilsson, M., ... Biddle, S. (2016). Physical activity for cognitive and mental health in youth: A systematic review of mechanisms. Pediatrics, 138(3), e20161642. PubMed ID: 27542849 doi:10.1542/peds.2016-1642 
Mahoney, J.L, Harris, A.L., \& Eccles, J.S. (2006). Organized activity participation, positive youth development, and the overscheduling hypothesis. SRCD Social Policy Report, 20(4), 1-31.

Mahoney, J.L., \& Vest, A.E. (2012). The over-scheduling hypothesis revisited: Intensity of organized activity participation during adolescence and young adult outcomes. Journal of Research on Adolescence, 22(3), 409-418. PubMed ID: 23066336 doi:10.1111/j. 1532-7795.2012.00808.x

Malina, R.M. (2009). Children and adolescents in the sport culture: The overwhelming majority to the select few. Journal of Exercise Science \& Fitness, 7(2 Suppl.), S1-S10.

Malina, R.M. (2010). Early sport specialization: Roots, effectiveness, risks. Current Sports Medicine Reports, 9(6), 364-371. PubMed ID: 21068571 doi:10.1249/JSR.0b013e $3181 \mathrm{fe} 3166$

McMahon, E.M., Corcoran, P., O’Regan, G., Keeley, H., Cannon, M., Carli, V., ... Wasserman, D. (2017). Physical activity in European adolescents and associations with anxiety, depression and well-being. European Child \& Adolescent Psychiatry, 26(1), 111-122. PubMed ID: 27277894 doi:10.1007/s00787-016-0875-9

Merglen, A., Flatz, A., Belanger, R.E., Michaud, P.-A., \& Suris, J.-C. (2013). Weekly sport practice and adolescent well-being. Archives of Disease in Childhood, 99(3), 208-210. PubMed ID: 24257080 doi:10.1136/archdischild-2013-303729

Oberle, E., Ji, X.R., Kerai, S., Guhn, M., Schonert-Reichl, K.A., \& Gadermann, A.M. (2020). Screen time and extracurricular activities as risk and protective factors for mental health in adolescence: A population-level study. Preventative Medicine, 141, 106291. PubMed ID: 33069689 doi:10.1016/j.ypmed.2020.106291

Panza, M.J., Graupensperger, S., Agans, J.P., Doré, I., Vella, S.A., \& Evans, M.B. (2020). Adolescent sport participation and symptoms of anxiety and depression: A systematic review and meta-analysis. Journal of Sport and Exercise Psychology, 42(3), 201-218.

ParticipACTION. (2020). 2020 ParticipACTION Report Card on Physical Activity for Children and Youth: The Role of the Family in the Physical Activity, Sedentary and Sleep Behaviours of Children and Youth. Retrieved from https://participaction.cdn. prismic.io/partcipaction/f6854240-ef7c-448c-ae5c-5634c41a0170_2020_Report_Card_ Children_and_Youth_Full_Report.pdf

Patte, K.A., Faulkner, G., Qian, W., Duncan, M., \& Leatherdale, S.T. (2020). Are one-year changes in adherence to the 24-hour movement guidelines associated with depressive symptoms among youth? BMC Public Health, 20(1), 793. PubMed ID: 32460742 doi:10.1186/s12889-020-08887-z

Pelletier, L., Shanmugasegaram, S., Patten, S.B., \& Demers, A. (2017). Self-management of mood and/or anxiety disorders through physical activity/exercise. Health Promotion and Chronic Disease Prevention in Canada: Research, Policy and Practice, 37(5), 149-159. PubMed ID: 28493659 doi:10.24095/hpcdp.37.5.03

Pluhar, E., McCracken, C., Griffith, K.L., Christino, M.A., Sugimoto, D., \& Meehan, W.P.I. (2019). Team sport athletes may be less likely to suffer anxiety or depression than individual sport athletes. Journal of Sports Sciences \& Medicine, 18(3), 490-496. PubMed ID: 31427871

Poitras, V.J., Gray, C.E., Borghese, M.M., Carson, V., Chaput, J.-P., Janssen, I., ... Tremblay, M.S. (2016). Systematic review of the relationships between objectively measured physical activity and health indicators in school-aged children and youth. Applied Physiology, Nutrition and Metabolism, 41(6), S1197-S1239. PubMed ID: 27306431 doi:10.1139/apnm-2015-0663

Radloff, L.S. (1977). The CES-D scale: A self-report depression scale for research in the general population. Applied Psychological Measurement, 1(3), 385-401. 
Randall, E.T., \& Bohert, A.M. (2009). Organized activity involvement, depressive symptoms, and social adjustment in adolescents: Ethnicity and socioeconomic status as moderators. Journal of Youth and Adolescence, 38(9), 1187-1198. PubMed ID: 19669899 doi:10.1007/s10964-009-9417-9

Remschmidt, H. (2013). Mental health and psychological illness in adolescence. Deutsches Ärzteblatt International, 110(25), 423-424. PubMed ID: 23840286 doi:10.3238/ arztebl.2013.0423

Rose, M.S., Emery, C.A., \& Meeuwisse, W.H. (2008). Sociodemographic predictors of sport injury in adolescents. Medicine \& Science in Sports \& Exercise, 40(3), 444-450. PubMed ID: 18379205 doi:10.1249/MSS.0b013e31815ce61a

Sabiston, C.M., Jewett, R., Ashdwn-Franks, G., Belanger, M., Brunet, J., O’Loughlin, E., \& O'Loughlin, J. (2016). Number of years of team and individual sport participation during adolescence and depressive symptoms in early adulthood. Journal of Sports \& Exercise Psychology, 38(1), 105-110. PubMed ID: 27018562 doi:10.1123/jsep.2015-0175

Shanahan, L., Copeland, W.E., Angold, A., Bondy, C.L., \& Costello, J.E. (2014). Sleep problems predict and are predicted by generalized anxiety/depression and oppopsitional defiant disorder. Journal of the American Academy of Child and Adolescent Psychiatry, 53(5), 550-558. PubMed ID: 24745954 doi:10.1016/j.jaac.2013. 12.029

Siefken, K., Junge, A., \& Laemmle, L. (2019). How does sport affect mental health? An investigation into the relationship of leisure-time physical activity with depresion and anxiety. Human Movement, 20(1), 62-74. doi:10.5114/hm.2019.78539

Slater, A., \& Tiggeman, M. (2011). Gender differences in adolescent sport participation, teasing, self-objectification and body image concerns. Journal of Adolescence, 34(3), 455-463. PubMed ID: 20643477 doi:10.1016/j.adolescence.2010.06.007

Smucny, M., Parikh, S.N., \& Pandya, N.K. (2015). Consequences of single sport specialization in the pediatric and adolescent athlete. Orthopedic Clinics of North America, 46(2), 249-258. PubMed ID: 25771319 doi:10.1016/j.ocl.2014.11.004

Snyder, A.R., Martinez, J.C., Bay, C.R., Parsons, J.T., Sauers, E.L., \& Valovcih McLeod, T.C. (2010). Health-related quality of life differs between adolescent athletes and adolescent nonathletes. Journal of Sport Rehabilitation, 19(3), 237-248. PubMed ID: 20811075 doi:10.1123/jsr.19.3.237

Spitzer, R.L., Kroenki, K., Williams, J.B., \& Löwe, B. (2006). Measure for assessing generalized anxiety disorder: The GAD-7. Archives of Internal Medicine, 166(10), 1092-1097. PubMed ID: 16717171 doi:10.1001/archinte.166.10.1092

Standage, M., Gillison, F.B., Ntoumanis, N., \& Treasure, D.C. (2012). Predicting students' physical activity and health-related well-being: A prospective cross-domain investigation of motivation across school physical education and exercise settings. Journal of Sport and Exercise Psychology, 34(1), 37-60. PubMed ID: 22356882 doi:10.1123/ jsep.34.1.37

Tabachnick, B.G., \& Fidell, L.S. (2019). Using multivariate statistics (7th ed.). Boston, MA: Pearson.

Twenge, J.M., \& Campbell, W.K. (2018). Associations between screen time and lower psychological well-being among children and adolescents: Evidence from a population-based study. Preventive Medicine Reports, 12, 271-283. PubMed ID: 30406005 doi:10.1016/j.pmedr.2018.10.003

Vigo, D., Thornicroft, G., \& Atun, R. (2016). Estimating the true global burden of mental illness. The Lancet Psychiatry, 3(2), 171-178. PubMed ID: 26851330 doi:10.1016/ S2215-0366(15)00505-2

White, V.M., Hill, D.J., \& Effendi, Y. (2004). How does active parental consent influence the findings of drug-use surveys in schools? Evaluation Review, 28(3), 246-260. PubMed ID: 15130183 doi:10.1177/0193841X03259549 
Wong, S.L., Leatherdale, S., \& Manske, S.R. (2006). Reliability and validity of a schoolbased PA questionnaire. Medicine \& Science in Sports \& Exercise, 38(9), 1593-1600. PubMed ID: 16960520 doi:10.1249/01.mss.0000227539.58916.35

Yang, J., Peek-Asa, C., Corlette, J., Cheng, G., Foster, D., \& Albright, J. (2007). Prevalence of and risk factors associated with symptoms of depression in competitive collegiate student athletes. Clinical Journal of Sport Medicine, 17(6), 481-487. PubMed ID: 17993792 doi:10.1097/JSM.0b013e31815aed6b

Zarrett, N., Fay, K., Li, Y., Carrano, J., Phelps, E., \& Lerner, R.M. (2009). More than child's play: Variable-and pattern-centered approached for examining effects of sport participation on youth development. Developmental Psychology, 45(2), 368-382. PubMed ID: 19271825 doi:10.1037/a0014577

Zhang, W., O'Brien, N., Forrest, J.I., Salters, K.A., Patterson, T.L., Montaner, J.S., . . Lima, V.D. (2012). Validating a shorted depression scale (10 item CES-D) among HIV-positive people in British Columbia, Canada. PLoS One, 7(7), e40793. PubMed ID: 22829885 doi:10.1371/journal.pone.0040793

Zimmerman-Sloutskis, D., Wanner, M., Zimmermann, E., \& Martin, B.W. (2010). Physical activity levels and determinants of change in young adults: A longitudinal panel study. The International Journal of Behavioral Nutrition and Physical Activity, 7, 2. PubMed ID: 20157439 doi:10.1186/1479-5868-7-2 